\title{
EXPERIMENTAL EVALUATION OF COIR MATS TO ENHANCE THE WEAK SUBGRADE SOIL UNDER REPEATED LOADING CONDITION
}

\author{
Dev Harinder ${ }^{1}$, Sabavath Shankar ${ }^{2}$ \\ ${ }^{1,2}$ Civil Department, National Institute of Technology, Warangal, Telangana, India
}

Received 9 November 2017; accepted 5 January 2018

\begin{abstract}
The performance and service life of the Low-volume roads (LVRs) largely depends on the properties of the subgrade and sub-base soil. The settlement, compressibility and bearing capacity characteristic of the LVRs associate with subgrade soil strength. The low shear strength subgrade soil poses several problems to the pavement service life. Such soil is notice as block cotton (BC) soil. The properties of BC soil are high swelling shrinkage, low bearing capacity and high settlement. The construction of pavement over such soil poses rutting fatigue and reflecting cracks to the pavement. To prevent this problem of pavement many of the conventional technics were adopted and reported their benefits for improving the service life of the pavement. But these techniques are not possible in all the case, than alternate stabilization methods are introduced by using the geosynthetic in pavement form the past few decades. The stabilization of pavement using the geosynthetics has gained universal promises to improve the service life of the pavement form the last four decades. In the present study, focus on the application of coir geotextile mats to improve the bearing capacity, reduce the settlement characteristic and the maintenance cost of LVRs over the weak subgrade soil.
\end{abstract}

Keywords: coir geotextile, subgrade, sub-base, reinforcement, separation, wheel tracking test.

\section{Introduction}

The reinforcement of soil mass in transportation and geotechnical area inserted with the fiber materials to improve its mechanical behavior has become popular. The primary function of reinforcement to the weak subgrade soil is to improving the stability of the pavement, by reducing the settlement and lateral deformation. The reinforcement or stabilization of pavement using the geosynthetics significantly increases the resistance of the pavement in terms of improving the bearing capacity of the weak subgrade soil. The deformation or rutting of the pavement without stabilization with geotextile significantly increases than compare non- stabilization of weak subgrade. The separation function of geotextile is more significant than the geogrid (Brandon et al., 1996).

The reinforcement of soil elements using the sheets, strips, rubber, and fiber is Asian techniques to stabilization of the weak subgrade to improve the service life of the LVRs. The performance of the pavement improved by insert the tensile element in the form of geotextile, which are abundantly available and widely used in many countries. These materials are locally available with low cost. In the present study, an attempt

${ }^{1}$ Corresponding author: harindergpd2017@student.nitw.ac.in 
is made to use the coir mats over the weak subgrade to enhance the bearing capacity at suitable position with appropriate sub-base soil to improve the life of the pavement with low maintenance cost.

\section{Literature Review}

The expansive soil subgrade experience several problems in the form of rutting, heaving and reflection due to their inherent volume change behavior upon wetting and drying condition (Brian et al., 2001; Arafat et al., 2015). Despite favorable properties of geosynthetics for their use in pavement construction, they proved to be cost effective especially for low volume roads (Yang et al., 2007). During past few decades, geosynthetics have gained universal attention across all possible types of soil subgrade either to overcome the subgrade deficiency or to enhance permanent life and performance (Al-Qadi et al., 2011; Ferrotti et al., 2011; Zornberg et al., 2009; Chaple et al., 2013) The study evaluate the reinforcement parameter of the coir geotextile in the laboratory using model tests on square footings supported on highly compressible clayey soil, effects on bearing capacity and settlement of the footing with provision of coir geotextile with adding of coir $0.25 \%, 0.5 \%, 0.75 \%$ \& $1.0 \%$ to the thickness of reinforced layer. The study revealed that the provision of coir reinforced layer significantly increase the bearing capacity of clay soil and the ultimate bearing capacity of reinforced section shown the better performance. (Mali and Singh, 2014) an attempt is made in the laboratory to study the behavior of cohesive soils reinforced with coir fibers, polypropylene fibers and scrap tire rubber fiber by the triaxial, direct shear and unconfined compression tests. The results are made as follows; the optimum fiber content $1 \%$, the shear strength of polypropylene is found to be $0.4 \%$, and optimum fiber length and fiber content are $10 \mathrm{~mm}$ and $2 \%$ respectively. (Durga Prashanth et al., 2012) conducted study to evaluate the deformation of reinforcement and un-reinforcement of model layer with accelerated pavement test over the problematic soil. Such soil is noticed that the $\mathrm{BC}$ soil content clayey and silty. The study found that the provision of coir mats improves the reinforcement, separation, filtration function of pavement. (Jairaj et al., 2013) study is carried out in the laboratory to reinforce the black cotton soils by using the coir geotextile with the help of Undrained triaxial. The present study, concluded that the reinforcement increases peak compressive strength, shear strength, and ductility. Increase in length of coir fiber increases cohesion and angle of internal friction. Increase in the fiber content beyond $2 \%$ poses mixing difficulty as soil lumps are formed during mixing this has led to decrease in peak shear strength. The study investigated that the polymeric geocell improves the performance of the unpaved roads over the poor subgrade, quarry dust shown the better performance than the other materials (Pokharel et al., 2011). To Studied the performance of the geo-grid reinforcement, indicates that the use of Geosynthetics in pavement over the poor subgrade soil tends to reduce the Sub Base thickness with increasing traffic volume (Adams et al., 2014). To addressing the problem of pavement, to prevent this problem this study is examine the coir geotextile mats can be effectively serves as reinforcement, separation, drainage materials over the weak subgrade soil for LVRs. The study is conducted under moving loading condition in the laboratory, to correlate the filed study by accelerated pavement test track (APT). 


\section{Materials Used for the Study}

To conduct the study in the laboratory black cotton soil is collected from the lake which is near to the NIT Warangal and used as a subgrade soil. The basic properties of $\mathrm{BC}$ soils are determine in the laboratory and given in Table 1 .

\section{Table 1}

The Basic Properties of BC Soil

\begin{tabular}{|l|c|}
\hline The Property of BC soil & Value \\
\hline Classification & 58 \\
\hline Liquid limit (\%) & 27 \\
\hline Plastic limit (\%) & 34 \\
\hline Plasticity index (\%) & 2.62 \\
\hline Specific gravity & 17 \\
\hline Optimum Moisture Content (\%) & 1.7 \\
\hline Max dry density (gm./cc) & 77 \\
\hline Free Swelling Index (\%) & 9 \\
\hline Un-soaked CBR value (\%) & 1 \\
\hline Soaked CBR value (\%) & \\
\hline
\end{tabular}

Generally morrum soil is commonly used materials in roads construction. The two types of the sub-base soil are considered in the present study such as morrum soil and uniformly grade sub-base soil. The properties of the sub-base soil are given in Table 2 .

\section{Table 2}

The Basic Properties of BC Soil

\begin{tabular}{|l|c|c|}
\hline The Properties of sub- Base materials & Sandy Gravel & Morrum \\
\hline Optimum Moisture Content (\%) & 8.0 & 10.0 \\
\hline Maximum Dry Density(MDD) & 1.87 & 1.94 \\
\hline Shear strength parameter (C and $($ ) & $0,31^{\circ}$ & $5,34^{\circ}$ \\
\hline Un Soaked CBR (\%) & 13 & 21 \\
\hline Soaked CBR (\%) & 6 & 9 \\
\hline
\end{tabular}

The coir geotextile is naturally available material extracted from the husk of coconuts. It is strong in the nature and high durability as compared with other natural material, it can spun and woven into matting. The basic properties of coir geotextile are presented in Table 3. 


\section{Table 3}

The Basic Properties of Coir Geotextile

\begin{tabular}{|l|c|}
\hline Basic Properties of the coir & Values \\
\hline Length $(\mathrm{mm})$ & $15-20$ \\
\hline Density $(\mathrm{g} / \mathrm{cc})$ & $1.15-1.4$ \\
\hline Breaking elongation $(\%)$ & 30 \\
\hline Diameter $(\mathrm{mm})$ & $0.1-1.5$ \\
\hline Specific Gravity & 1.15 \\
\hline Rigidity modulus $($ dynes $/ \mathrm{cm})$ & 1.8924 \\
\hline Swelling in water $(\%)$ & 5 \\
\hline Young's modulus $\left(\mathrm{GN} / \mathrm{m}^{2}\right)$ & 4.5 \\
\hline Specific heat & 0.27 \\
\hline
\end{tabular}

In the present study, three types of coir geotextile mats are used which are shown in Fig. 1. Namely,

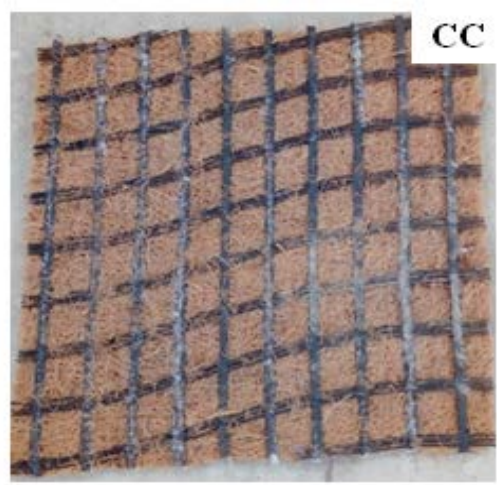

Fig. 1.

Coir Mats used in the Present Study

\section{Experimental Setup}

The Wheel Tracking Test apparatus (WTT) are used for this investigation with varying contact pressure of moving load to simulate the filed condition. It was developed by British National Rail Road Research Institute (generally used for measuring the plastic deformation of bituminous asphalt concrete). The WTT apparatus height of the loading
$\mathrm{CC}=$ Coir Composite, $\mathrm{WCM}=$ Woven Coir Mat and NWCM= Non-Woven Coir Mat.

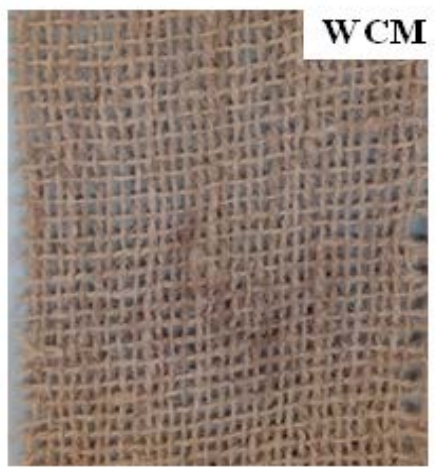

lever has been raised using the fabricated angle sections. The fabricated angles are controlling the enable to the loading onto pavement model section. The maximum load applied on to the pavement has $55 \mathrm{Kg}$, through the moving wheel of diameter $200 \mathrm{~mm}$, width of $50 \mathrm{~mm}$ made of solid rubber. To run the wheel over the model section three phase motor with $75 \mathrm{kw}, 400 \mathrm{v}$ power motor is used. The experimental setup is show in Fig. 2 . 


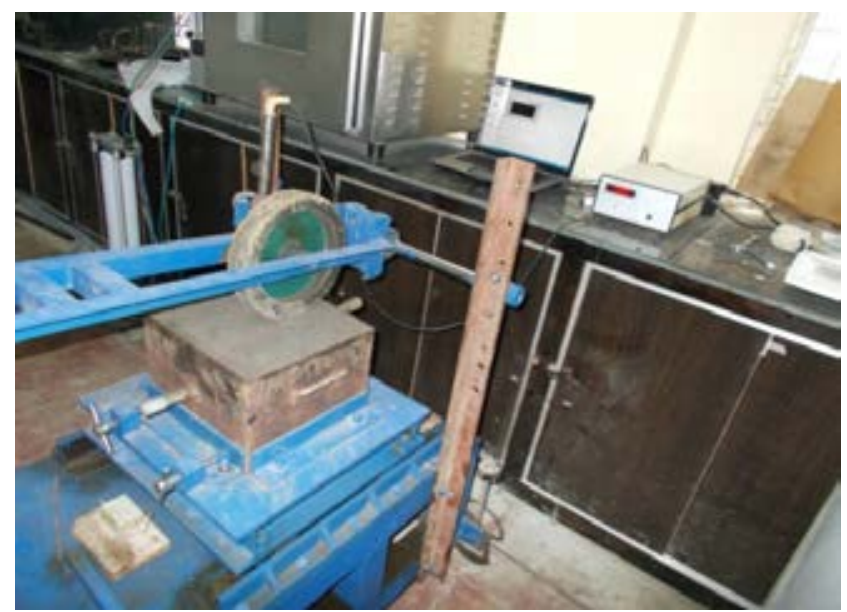

Fig. 2.

Experimental Setup used for the Study

\section{Results and Discussion}

The laboratory study is performed using the fabricated mould of size $300 \mathrm{~mm} \times 300 \mathrm{~mm} \times 300 \mathrm{~mm}$. The fabricated mould was prepared as a two-layer pavement model system as per the modified CBR protocol.
The coir mats are placed between the subgrade and sub-base at a height of $\mathrm{H} / 2, \mathrm{H} / 3$ and $\mathrm{H} / 4$ position. The two types of the coir mats were used as reinforcement material. The model layer as compacted as subgrade and sub-base of BC soil and sandy gravel soil respectively, tested by using the WTT apparatus.

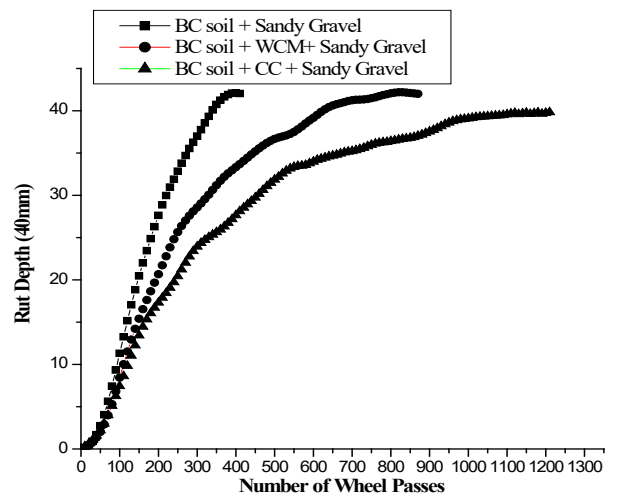

Fig. 3.

Rut Depth along with Number of Wheel Passes at H/2 Position 
The laboratory study is conducted, in order to determine the deformation of reinforced and un-reinforced model layer at $\mathrm{H} / 2$ position of fabricated mould. The unreinforced model layer higher deformation occurs at lower repetition than the reinforced model layer. The higher repetition (1250) is noticed with $\mathrm{CC}$ materials at $\mathrm{H} / 2$ position. The un-reinforcement pavement layer showed the 350 repetition. In that case higher the thickness of sub-base material is placed over the coir mats. The rut depth along with the number of wheel passes at $\mathrm{H} / 2$ is shown in Fig. 3.

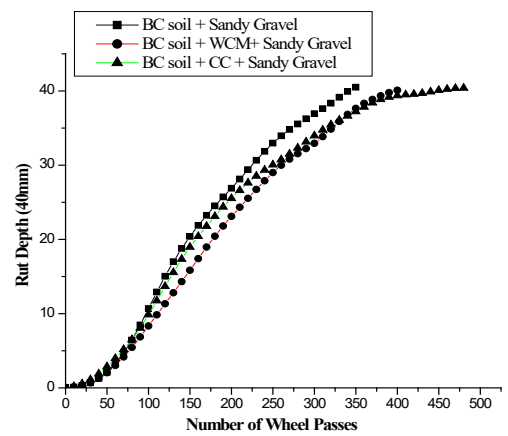

Fig. 4.

Rut Depth along with Number of Wheel Passes at H/3 Position

In this case, the coir mats are placed in between the subgrade and sub-base at a height of $\mathrm{H} / 3$ position with reducing the thickness of sub-base soil than the $\mathrm{H} / 2$ position. At this particular location the failure are noticed in sandy gravel sub-base soil, due to its lower shear strength $\mathrm{C}$ and $\phi$ are 0 and $31^{\circ}$ respectively. The strength of the sub-base soil greatly influences the load distribution over the subgrade. The maximum repetition are 480 occurs at this position with the CC materials higher than the WCM. The rut depth along with number of wheel passes at $\mathrm{H} / 3$ position shown in Fig. 4 .

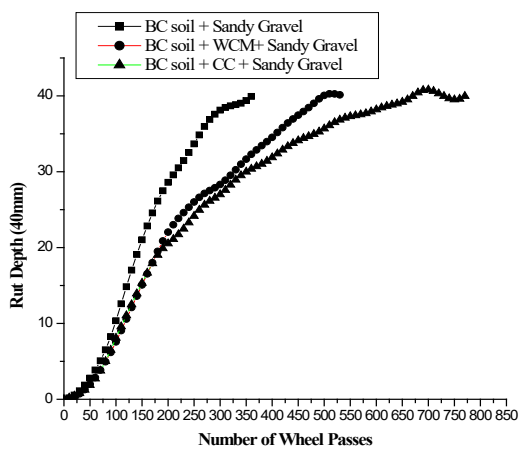

Fig. 5.

Rut Depth along with Number of Wheel Passes at H/4 Position 
The fabricated mould was prepared with provision of coir mats at $\mathrm{H} / 4$ position while reducing the sub-base soil thickness and measured the deformation of the prepared mould. The $40 \mathrm{~mm}$ deformation is noticed for maximum repetition 840 of $\mathrm{CC}$ coir mats at $\mathrm{H} / 4$ position. The reinforce model layer repetition are more significant than the un-reinforced model layer. In this case the provision of coir mats acts as more effective in tension member and transferred towards the edge of the pavement. The provided coir mats at $\mathrm{H} / 4$ position near to the wheel load is more significant to transfer the load coming from the top of the sub-base layer. Due to this phenomenon, the load and stress over the over the weak subgrade is reduced and improved the repetition and performance of the LVRs. The rut depth and number of wheel passes at $\mathrm{H} / 4$ position given in Fig. 5.

Similarly, the fabricated mould was prepared with inclusion of coir mats at $\mathrm{H} / 2, \mathrm{H} / 3$ and $\mathrm{H} / 4$ position in between subgrade and sub-base soil. The test is performed in the laboratory, to determine the appropriate placement position of coir mats with suitable types of sub-base soil. The pavement model layers were prepared with the $\mathrm{BC}$ soil as subgrade and morrum soil as sub-base with and without reinforcement of coir mats. The deformation of the fabricated mould is noticed along with their wheel passes.

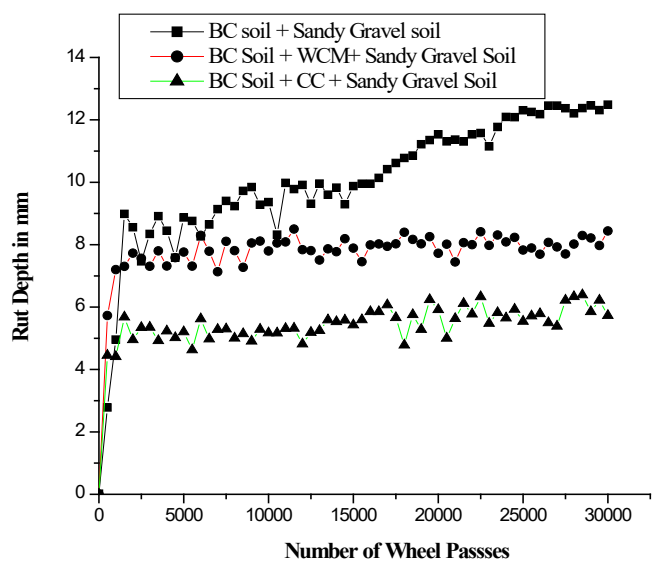

Fig. 6.

Rut Depth and Number of Wheel Passes at H/2

The study was carried out in the laboratory in the form of two-layer model system. The pavement layer, the coir mats are placed at $\mathrm{H} / 2$ position with morrum soil sub-base. The deformation of the reinforced and unreinforced model layer noticed for $\mathrm{T} 1$ traffic categories $(T 1=30,000)$. During the study it was noticed that the provision of coir mats with well graded morrum soil increase the repetition and reaches up to $\mathrm{T} 1$ traffic categories. The deformation or rut depth of the un-reinforced sample is $15 \mathrm{~mm}$ and the reinforced sample $4 \mathrm{~mm}$ was noticed. The provided CC mats reduce the deformation up to $11 \mathrm{~mm}$. The rut depth and number passes at $\mathrm{H} / 2$ position is shown in Fig. 6. 


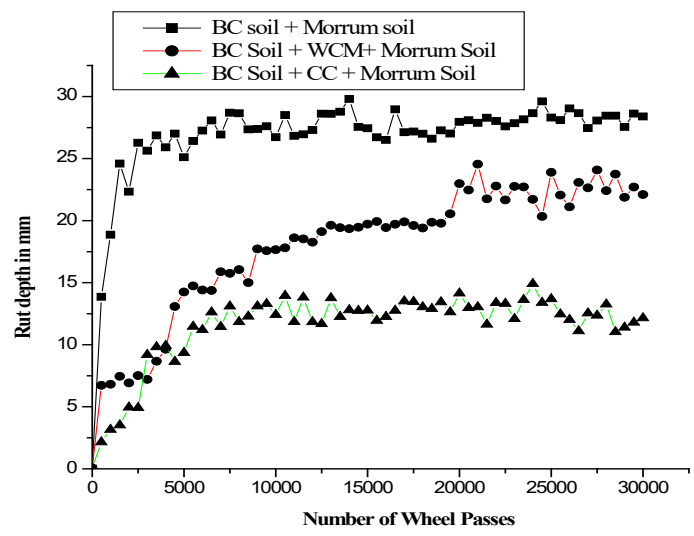

Fig. 7.

Rut Depth and Number of Wheel Passes at $\mathrm{H} / 3$

From the test it was observed that the maximum and minimum rutting of unreinforcement two- layer model section is occurs at a position of $\mathrm{H} / 3$ position are $27 \mathrm{~mm}$ and $8 \mathrm{~mm}$ respectively. The reinforcement pavement model layer with $\mathrm{CC}$ mats at $\mathrm{H} / 4$ with reducing the thickness of the morrum sub-base soil reduces the deformation and increases the repetition.
The minimum rut depth of coir mats are occurs at $\mathrm{h} / 4$ position with CC. In case of morrum as a sub-base soil, the provision of CC, WCM and NWCM mats are shown the less rutting when compared with sandy gravel soil. Increasing the thickness of the sub-base soil materials reduce the rut depth. Rut depth and number of wheel passes at $\mathrm{H} / 3$ at position is shown in Fig. 7 .

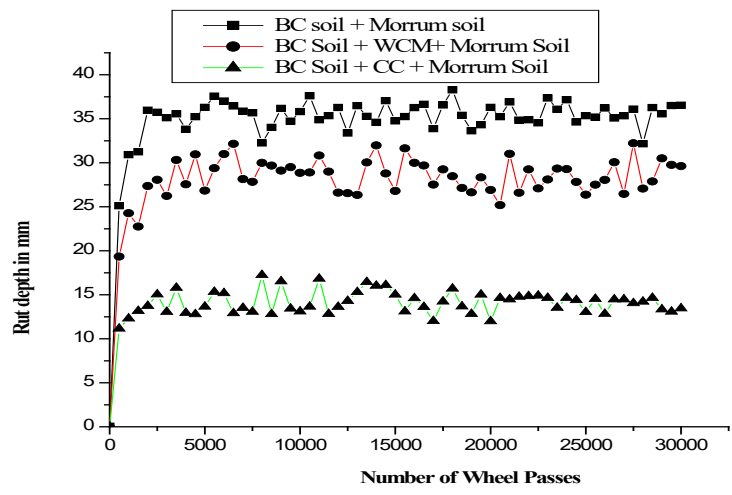

Fig. 8.

Rut Depth and Number of Wheel Passes at H/4 
The two-layer model pavement system was prepared in order to reduce the thickness of the sub-base soil and the coir mats are provided at $\mathrm{H} / 4$ position. The maximum and the minimum rut depth of reinforced and un-reinforced model layer deformation are noted as $37 \mathrm{~mm}$ and $11 \mathrm{~mm}$ respectively. The un-reinforced model layer rut depth at $\mathrm{H} / 4$ position shown in Fig. 8. The inclusion of coir mats in between subgrade and sub-base with sub-base as a morrum soil showed the better performance than compared with the sandy gravel soil. From experimental study were concluded that the higher thickness of coir mats helps to settle the pavement section slowly. The placement of the coir geotextile mats with well-graded soil increases the performance and service life of the pavement structure.

\section{Conclusion}

In the laboratory, the comparison study between the two types of fabricated mould with two types of varying thickness of sub-base has been down. The following conclusions are drawn from the study.

- The maximum repetition were found with morrum soil with reinforcement of coir composite mate with minimum deformation $13 \mathrm{~mm}$ with reducing the sub-base thickness at $\mathrm{H} / 4$ position;

- The reinforcement and un-reinforced pavement model layer reaches the $\mathrm{T} 1$ traffic categories with morrum soil with varying deformation, which not occur in case of sandy gravel soil with increasing the sub-base thickness due its low shear strength parameter $\mathrm{C}$ and $\phi$;

- The coir composite material acts as reinforcement and separation material in both the case of soil, the WCM gives the less reinforcement than the $\mathrm{CC}$ and also fails in provide the separation function;
- The coir geotextile are need to place near to wheel load so that it can carry the maximum load and transferred away from the subgrade. It can reduce the subgrade deformation and improved the pavement service life.

The observation made as a part of this work will have an important to use the naturally available materials for the construction of LVRs over weak sub-grade soil. The coir mats can be effectively used since the fiber allows pore water pressure to dissipate easily when subjected to overburden pressure.

\section{References}

Adams, C. A.; Amofa, N. Y.; Opoku-Boahen, R. 2014. Effect of Geogrid Reinforced Subgrade on Layer Thickness Design of Low Volume Bituminous Sealed Road Pavements, International Refereed Journal of Engineering and Science 3(7): 59-67.

Al-Qadi, I. L.; Dessouky, S.; Tutumluer, E.; Kwon, J. 2011. Geogrid mechanism in low volume flexible pavements: accelerated testing of full-scale heavily instrumented pavement sections, International Journal of Pavement Engineering 12(2): 121-135.

Albrecht, B. A.; Benson, C. H. 2001. Effect of desiccation on compacted natural clays, Journal of Geotechnical and Geoenvironmental Engineering 127(1): 67-75.

Arafat, H.; Ebid, A. M. 2015. Optimum Replacement Depth to Control Heave of Swelling Clays, International Journal of Engineering and Innovative Technology (IJEIT) 4(9): 73-81.

Brandon, T.; Al-Qadi, I.; Lacina, B.; Bhutta, S. 1996. Construction and instrumentation of geosynthetically stabilized secondary road test sections, Transportation Research Record: Journal of the Transportation Research Board 1534: 50-57. 
Chaple, P. M.; Dhatrak, A. I. 2013. Performance of Coir fiber Reinforced Clayey Soil, The International Journal of Engineering and Science 2(4): 54-64.

Durga Prasanth, L.; Santosh, G. 2012. Accelerated consolidation of coir reinforced lateritic soils with vertical sand drains for pavement foundations, International Journal of Engineering Research and Application 2(4): 916-923.

Ferrotti, G.; Canestrari, F.; Virgili, A.; Grilli, A. 2011. A strategic laboratory approach for the performance investigation of geogrids in flexible pavements, Construction and Building Materials 25(5): 2343-2348.

Jairaj, C.; Prathap, M. T. 2013. Effect of length of coir fiber on strength of lime treated block cotton soil. In Proceedings of Indian Geotechnical Conference, December 22-24, Roorkee.
Mali, S.; Singh, B. 2014. Strength behavior of cohesive soil reinforced with fibers, International Journal of Civil Engineering Research 5(4): 353-360.

Pokharel, S.; Han, J.; Manandhar, C.; Yang, X.; Leshchinsky, D.; Halahmi, I.; Parsons, R. 2011. Accelerated pavement testing of geocell-reinforced unpaved roads over weak subgrade, Transportation Research Record: Journal of the Transportation Research Board 2204: 67-75.

Yang, S. H.; Al-Qadi, I. L. 2007. Cost-effectiveness of using geotextiles in flexible pavements, Geosynthetics International 14(1): 2-12.

Zornberg, J. G.; Gupta, R. 2009. Reinforcement of pavements over expansive clay subgrades. In Proceedings of the 17th International Conference on Soil Mechanics and Geotechnical Engineering, 765-768. 